\title{
Trabajadoras, artesanos y mendigos. Una aproximación a las experiencias sociales de trabajo y pobreza en la Buenos Aires de la primera mitad del siglo XIX
}

\author{
Workers, artisans, and beggars. An approach to the social experiences of work and poverty in Buenos Aires during \\ the first half of the 19th century
}

\author{
Gabriela Mitidieri \\ Universidad Nacional de Buenos Aires, Argentina \\ gmitidieri@gmail.com
}

Valeria Silvina Pita

CONICET, Argentina

vspita@gmail.com

\section{Resumen:}

En el presente artículo se indaga en torno a trayectorias de mujeres y varones a mediados del siglo XIX en Buenos Aires, en cuyas vidas trabajo y pobreza se entrelazaron como parte de sus experiencias de supervivencia. La fuente que se trabaja es un libro de ingresos y observaciones del Asilo de Mendigos de la Municipalidad. Al poner el foco en las trayectorias laborales de los y las asiladas en este momento histórico, sus lugares de origen, su identidad racial, es posible poner en tensión las clásicas divisiones de la historia del trabajo: las dicotomías entre trabajo y pobreza; la división entre trabajo libre y trabajo esclavo; y el divorcio entre el llamado trabajo productivo y el trabajo de servir llevado adelante en las casas. También pone en duda la noción de especialización/ calificación como camino de movilidad ascendente, así como la utilidad de ciertas periodizaciones establecidas para pensar los mundos del trabajo a mediados del siglo XIX en Argentina, que no han incluido dimensiones racializadas y engenerizadas.

Palabras Clave: Mundos del trabajo, Siglo XIX, Pobreza, Trabajo artesanal, Género, Raza, Buenos Aires, Asilo de Mendigos.

\section{Abstract:}

This article explores trajectories of women and men in the mid-nineteenth century in Buenos Aires, in whose lives: work and poverty were intertwined as part of their survival experiences. The documentary source is a book of income and observations of Asilo de Mendigos of the Municipality. By focusing on the labor trajectories of those who have been isolated in this historical moment, their places of origin, their racial identity, it is possible to put into tension the classic divisions of the history of work: the dichotomies between work and poverty; the division between free labor and slave labor; and the divorce between the so-called productive work and the work of serving carried forward in the houses. It also calls into question the notion of specialization / qualification as a path of upward mobility, as well as the usefulness of some periodization established to think about the worlds of work in the mid-nineteenth century in Argentina, which have not included racialized and engenerized dimensions.

KEYWORDS: Work, 19th century, Poverty, Craft work, Gender, Race, Buenos Aires, Asylum of Beggars.

\section{INTRODUCCIÓN}

En la mañana del 12 de octubre de 1858, Rosa Represa fue ingresada al aún no oficialmente inaugurado Asilo de Mendigos de la ciudad de Buenos Aires, en el sitio que previamente fuera ocupado por el convento de los Recoletos. En aquel momento, un escribiente municipal asentó en un cuaderno que la mujer tenía unos 50 años, era de origen africano, lavandera y que sufría de dolores reumáticos. En el mismo registro dejó constancia de que era "libre desde tiempos de Rosas", que había servido en la casa de un hombre de apellido Barruti y que luego había comenzado a ganarse la vida como lavandera en un campamento militar. Rosa había quedado coja de una pierna y se desplazaba con muletas. Al momento de su ingreso al asilo, su estado era andrajoso. El 17 de octubre, día oficial de la inauguración del Asilo, fue admitido el pardo Mariano Reinoso,

Recepción: 11 de diciembre de 2018 | Aprobación: 26 de febrero de 2019 | Publicación: 28 de mayo de 2019 
un zapatero de 54 años que declaró haberse ganado la vida con su oficio hasta 1840, año en el que fue llamado al servicio de las armas, donde se lo destinó a tareas de cocina. ${ }^{2}$ Quedó escrito que había perdido la vista en esa etapa y que, desde entonces, había sido sostenido por su madre, hasta su fallecimiento en el año 1851. Reinoso declaró también que tenía familia, un hermano político y dos hijas mujeres que trabajaban de costureras. Unas semanas más tarde, ingresó al Asilo la negra María Carreras de 80 años de edad. Nacida en Brasil, dijo haber servido como esclava hasta tiempos de Rosas, a lo que el escriba agregó "en que fue libre como las de esta condición", 3 dando a entender que María habia ganado su libertad como parte de una política del rosismo, leyenda que repitió en el mismo cuaderno varias veces. María no tenía hijos ni parientes y declaró que no había pedido limosna en su vida.

Las historias de Rosa, María y Mariano se entrecruzaron con otras en el año 1858, cuando luego de idas y vueltas, el municipio de Buenos Aires inauguró una institución destinada a albergar a hombres y mujeres pobres, enfermas, y sin redes familiares que deambulaban por distintos sitios de la ciudad. De los primeros meses de funcionamiento de esa institución llamada Asilo General de Mendigos, quedó un cuaderno de tapas verdes que no forma parte de los fondos municipales sino del Archivo General de la Nación, en cuya portada está escrito a mano Asilo de Mendigos. Allí se hallan las huellas de las trayectorias de vida y de trabajo de ciento cincuenta y nueve mujeres y varones ingresados entre octubre de 1858 y agosto de 1859. El cuaderno está subdividido en dos partes. Una primera consiste en un listado de las personas asiladas con los datos de: fecha de ingreso, número de orden interno, nombre y apellido, sexo, edad, color, estado civil, patria, religión, profesión, observaciones y salida. Una segunda parte, se refiere a las mismas personas registradas anteriormente y con datos sobre sus vidas a lo largo del tiempo. Esta información proporciona pistas sobre las trayectorias laborales y vitales de las personas reseñadas, referencias a sus grupos familiares, sus vínculos conyugales, sus estatus legales. También en esas descripciones aparecen menciones a acontecimientos políticos que fueron significativos en sus biografías, como levas, conquista de la libertad, desempeño en el ejército, migraciones internas ligadas a la propia ocupación, estado de salud, redes de sostenimiento en situación de enfermedad o invalidez. Su lectura permite reconstruir una diversidad de experiencias que hacen a las biografías laborales de estas personas a lo largo de la primera mitad del siglo XIX, transformándose en un documento clave para la historia social del trabajo.

La historiografía local se interrogó por las vidas de personas lisiadas, ancianas, incapacitadas para trabajar como Rosa, María y Mariano. Lo hizo como parte de los estudios de la pobreza urbana y las políticas de la elite en torno a pobres y mendigos. En las siguientes páginas nos proponemos reflexionar sobre algunas de las posibilidades que este tipo de evidencias generan para la historia social del trabajo, en particular para estudiar trayectorias de vida y de trabajo. Estos testimonios son fragmentarios, como todas las fuentes, aunque se presenten o sean presentadas por quienes hacen historia como lo contrario. Pese al carácter parcial, acotado de la evidencia, esta permite seguir el rastro de las nociones que dichos sujetos construyeron sobre su experiencia laboral a lo largo de su vida. Su ingreso al asilo y los trabajos que desempeñaron hacen posible pensar las distintas formas de ganarse el sustento para estos adultos y adultas mayores, configurando un espacio laboral con sujetos que no son usualmente ponderados por la historiografía: viejas y viejos trabajadores.

Nuestra intención es problematizar algunos recorridos historiográficos a la luz de determinadas preguntas que pueden hacerse (entre otras) a este cuaderno y que entendemos permiten revisar relaciones, periodizaciones y problemas históricos. Así, al acompañar las complejas relaciones entre pobreza y trabajo; los mundos del trabajo artesanal y las relaciones de género y de raza; y los trabajos del servir, es posible enlazar dimensiones que han sido objeto de estudio de diversas líneas historiográficas, pero que, en las vidas de las personas en el pasado, fueron de la mano. Al hacerlo, esperamos poder poner en tensión las periodizaciones que han organizado a este mundo del trabajo de mediados del siglo XIX, al estudiarlo siguiendo la pista de los acontecimientos políticos. También procuramos observar las fronteras que escindieron al trabajo libre y esclavo, a la calificación y a la pobreza, al trabajo productivo de los del servir en las casas. Las trayectorias de quienes dejaron sus huellas en ese cuaderno de tapas verdes hacen posible otear mundos del trabajo, 
relaciones y experiencias móviles y fluidas, atravesados por guerras, cambios políticos, discriminaciones raciales, violencias varias y la zozobra de unos tiempos en los cuales el ganarse la vida demandó estrategias diversas.

\section{Pobreza y TRABAJO ¿EXPERIENCIAS DIVORCIADAS?}

Juana María Achabal dijo tener 80 años al momento de ser ingresada por un hombre del municipio al Asilo de Mendigos. En el listado de la primera parte del cuaderno de ingresos quedó anotada como negra, africana y de profesión sirvienta. Pero, en la segunda parte del registro se escribieron otras cosas. Juana declaró que había sido esclava de un tal Blas Achabal, de quien llevaba el apellido, y lo era desde "la guerra de los ingleses", ${ }^{4}$ es decir, el recuerdo sobre su esclavización en el Río de la Plata se remontaba a la primera década del siglo XIX, y era anterior al ciclo revolucionario y a las luchas por la independencia. No sabemos cuándo ni cómo Juana fue trasladada a Santiago del Estero, donde pasó años en la casa de su propietario criando a los hijos de este. En algún momento, salió de esa provincia del norte y se radicó en la ciudad de Buenos Aires. Pedía limosnas desde hacía "mucho tiempo", y con ellas pagaba un cuartito en los fondos de la quinta de Guido. Su historia compartía rasgos con otras que ahí quedaron reseñadas en las cuales trabajo y pobreza se fundían.

En las historias o retazos de historias de ese cuaderno de tapas verdes, hombres y mujeres, esclavos o esclavas, artesanos, ${ }^{5}$ sirvientes, costureras, militares, en algún momento de sus vidas habían dejado de trabajar por distintas razones y habían atravesado la experiencia de pedir limosnas. Miguel Bosh declaró tener 61 años de edad, ser de origen maltés y marinero de oficio. También sobrevivía de mendigar desde que había quedado ciego y estaba impedido de trabajar. ${ }^{6}$ El africano Francisco del Pino, que expuso tener 100 años de edad y haber sido esclavo del virrey de dicho apellido, también vivía del socorro. Además de haber sido esclavo, había trabajado como cocinero y había oficiado de soldado durante las luchas por la independencia. Según comunicó, en la campaña de Chile quedó manco, "de resultas de una herida en el campo de batalla". ${ }^{7}$ Desde su retorno a Buenos Aires, fue auxiliado por personas que lo conocían y que según declaró "lo llevaban a su casa para darle alimentos". Al momento de su ingreso al Asilo estaba ciego y nada sabía de sus parientes a quienes no veía desde hacía mucho tiempo y quienes "nunca" lo habían cuidado en la enfermedad.

Historias como estas forman parte de los estudios de la pobreza, la marginación social y el pauperismo. En Argentina el desarrollo de estas líneas historiográficas ha sido acotado. No obstante, en distintos momentos, historiadores e historiadoras coloniales u otros abocados al siglo XIX se preguntaron por cómo hombres y mujeres afrontaron sus situaciones de precariedad material, de enfermedad, de abandono cuando carecían de casa, abrigo, familia y redes (Rebagliati, 2013; Johnson, 2011; Cruz, 2013; Parolo, 2005-2006; Mallo, 2004) ¿Qué significaba ser pobre en la aldea de Buenos Aires a fines del siglo XVIII, a comienzos del siglo XIX o en la segunda mitad del siglo XIX? ¿Quiénes eran los pobres? ¿Cómo esas personas habían caído en la pobreza, la indigencia o el pauperismo? También diversos estudios se preocuparon por saber cuáles fueron las respuestas públicas y privadas ante la miseria y la indigencia, y cómo los y las indigentes eran observados por las elites.

Hace unos años, el demógrafo e historiador José Luis Moreno trabajó con la evidencia que se presenta en este artículo (Moreno, 2012). Lo hizo para dar cuenta de los mendigos y las mendigas y sus historias de vida, desmenuzando la serie documental que constituye este cuaderno de tapas verdes para dar cuenta de sus características más constantes. Se preguntó por cómo estaba distribuida la población del asilo; si blancos y afrodescendientes habían recibido ayuda pública en términos semejantes o si los segundos habían sido discriminados, teniendo en cuenta cómo operaba la exclusión social en tiempos coloniales y revolucionarios. Segregó los datos y construyó cuadros con porcentajes indicando la distribución entre varones y mujeres, blancos y afrodescendientes, sus oficios. Su indagación, heredera de otras que venía desarrollando desde tiempo atrás, forma parte de los estudios históricos de la pobreza. Dichos análisis describen las características de la pobreza, ciclos, dinámicas y las respuestas oficiales y de particulares para 
paliarla. Moreno denominó a esas respuestas como "la política social antes de la política social" (Moreno, 2000). Bajo esta designación ingresaron en su investigación distintas prácticas como la caridad, la filantropía, la beneficencia y los programas públicos de las primeras décadas del siglo XX. El Asilo municipal de Mendigos, primera institución asistencial pública de este tipo en Buenos Aires, concitó la atención de este especialista, quien la consideró como una respuesta al conflicto social que mendigos y mendigas, al circular libremente por la ciudad, despertaban en la elite liberal. Este historiador igualmente distinguió en dicha decisión un intento político de un grupo de liberales, que buscaban hacerse un lugar en el escenario político porteño a la caída del rosismo, de dar solución a un problema desde una filosofía laica que entró en tensión con las visiones cristianas y que comportó a su vez una mirada renovada sobre la pobreza y los y las pobres.

Otras líneas de pesquisa se centraron en las estrategias de hombres y mujeres pobres para afrontar sus penurias y miserias. Investigaciones del periodo colonial y de la primera mitad del siglo XIX se interrogaron sobre cómo esclavos y esclavas, libertos y libertas, afrodescendientes, pardas y morenos, recurrieron a la Justicia para demandar por lo que entendían que les correspondía como derecho ante las promesas incumplidas de amos y amas en situaciones como la enfermedad, la manutención de los familiares ancianos, la libertad, o formas de abuso y maltrato. Dichas demandas, además de haber sido interpretadas como formas de visibilizar la agencia histórica, han permitido describir dimensiones de la vida cotidiana de estas personas y reconocer las serias dificultades para la supervivencia que atravesaban (Candioti, 2010; Secreto, 2010 y 2013; Saguier, 1989, 1995 y 1997; Rosal, 2006; Johnson, 2007 y 2013 y Bentancur y Aparicio, 2006).

Algunos estudios recientes se enfocaron en otro tipo de evidencias llamadas "informaciones de pobreza" para el periodo colonial y primeros tiempos independientes o "certificados de pobreza” en la segunda mitad del siglo XIX (Rebagliati, 2013; Pita, 2013 y 2018). Estos papeles, que en tiempos coloniales y durante las primeras décadas independientes eran un trámite judicial, se transformaron luego en una certificación más lábil firmada por hombres de iglesia, jueces de paz, comisarios de policía, funcionarios municipales o personas consideradas notables, quienes aseveraban el estado de carencia de otra persona y su imposibilidad para afrontar la supervivencia diaria. Una de las peculiaridades de estos escritos era que quienes los solicitaban buscaban ser reconocidos públicamente como pobres, pues contar con esa declaración permitía litigar sin costos en los tribunales menores (Rebagliatti, 2013). Más entrado el siglo XIX, un certificado permitía obtener una cama en un asilo u hospital o gestionar ante la caridad o beneficencia pública algún auxilio o ayuda económica (Pita, 2018). Las "informaciones de pobreza" involucraron en su confección a funcionarios y a testigos que declaraban públicamente sobre las condiciones de vida de los y las peticionantes. Los certificados de pobreza de la segunda mitad del siglo XIX también implicaban una serie de pasos, de idas y vueltas. Aunque más laxos en sus formas, estos papeles ponían de relieve las capacidades de las y los peticionantes para movilizar en su favor declaraciones de vecinos notables, curas párrocos, jueces de paz o por el contrario revelaban la ausencia conocidos y redes. Estas investigaciones, que forman parte de una agenda historiográfica reciente, indicaron quiénes eran los peticionantes, en qué condiciones llegaban a pedir sus informaciones de pobreza y de qué raza u origen nacional eran. A su vez, se orientaron hacia el reconocimiento de las características de la pobreza como constructo social, es decir cómo se entendía que era ser pobre, sobre todo qué entendían las élites que era ser pobre, reconociendo cuáles eran los principales discursos sobre la pobreza y dando historicidad a las definiciones de "pobre", "miserable", "pobre vergonzante", "pobre de solemnidad", "desvalido", etc.

Últimamente, unas otras pesquisas optaron por leer en este tipo de fuentes, con expresiones y fórmulas repetidas, los pasos dados por mujeres que los gestionaron, preguntando por cómo presentaron sus circunstancias de vida y sus trayectorias laborales. La pobreza y los mundos del trabajo se encontraron al intentar reconocer detrás de esas demandas, estrategias de supervivencias. En particular, estos trabajos rastrearon en las experiencias de mujeres que se presentaban públicamente como trabajadoras y a la par como pobres. Además de los certificados de pobreza, se sumaron cartas, informes varios, para preguntar cómo entendieron esas mujeres sus vidas y sus trabajos, los cambios en sus vidas, las maneras en que ellas se 
vincularon con filántropos y benefactoras, funcionarios públicos, personas de la elite, para intentar de este modo reconstruir históricamente sus márgenes de acción y agencia histórica (Pita, 2015 y 2018).

Esta historiografía puso de relieve cómo hombres y mujeres en dispares momentos históricos y en diferentes circunstancias se vieron envueltos y envueltas en la zozobra cotidiana de carecer de lo básico para la supervivencia. Esto podía involucrar no tener un techo, no tener abrigo, carecer de comida, calzado, medicinas. También podía significar carecer de trabajo, estar imposibilitado por una dolencia o por la edad para trabajar, entre otras situaciones como la orfandad, la viudez o el abandono del cónyuge. Estas penurias, carencias, pérdidas e impedimentos también formaron parte de las vidas de los y las trabajadoras en el pasado. Por ello, es posible volver próximas algunas preguntas y debates que se han gestado de modo independiente entre la historia política de la pobreza y la historia social del trabajo.

Las conexiones entre trabajo y pobreza se vuelven perceptibles al formular la pregunta. $\mathrm{Al}$ retornar a las historias de la esclava Juana María Achaval, del maltés Miguel Bosh y del africano Francisco del Pino, en sus declaraciones se detecta que, ante el interrogatorio del empleado municipal sobre su profesión, respondieron especificando lo que habían hecho en el pasado para vivir, en dónde habían llevado adelante su trabajo y ante qué circunstancias habían dejado de hacerlo. Sus vidas como esclavas y esclavos, sirvientes, marineros, cocineros y sus presentes como mendigos y mendigas no se desplegaron como experiencias divorciadas entre sí. Para ellos y ellas, en sus vidas, haber sido esclava y sirvienta de Achaval en Santiago del Estero y pedir limosnas para comer y pagar un cuartito en una finca de las afueras de la ciudad o trabajar de marinero hasta que la invalidez no lo permitió más no supuso reconocerse en una sola experiencia de sobrevivencia. Por el contrario, la historiografía marcó mayores distinciones. Aunque los estudios sobre la pobreza han partido de una serie de consideraciones comunes en torno a las relaciones entre trabajo y pobreza, entre las que se entendió que esta última era una experiencia por la que atravesaba la mayor parte de las personas, las conexiones no siempre se efectuaron. Tampoco el reconocimiento de que la mayoría de los que trabajaban seguían siendo pobres o que los y las pobres trabajaban o lo habían hecho en algún momento de sus vidas ya sea por un salario o por un plato de comida, un sitio donde dormir, entre otras posibilidades, generó enlaces. En estas ciento cincuenta y nueve historias de vida compiladas en un cuaderno hay elementos para pensar que las conexiones entre trabajo, marginación social y pobreza fueron parte central en las trayectorias de vida y de trabajo de aquellos y aquellas que, hacia el final de sus días, sin casa, familias de acogida, enfermos, pobres o inválidos pasaron por el Asilo.

\section{Huellas de Negros, Pardos y AFRicanas EN EL MUNDO DEL TRABAJO ARTESANAL}

El 27 de mayo de 1858 ingresó al Asilo, andrajoso y con una nota del Departamento de Policía, una sola persona, Juan Manuel Posadas, un anciano de 80 años que declaró ser zapatero y haber servido en el ejército al mando de Manuel Belgrano en las batallas de Ayohuma (1813) y en Sipe Sipe (1815) en el Regimiento N. 6 de Pardos y Morenos. Posadas había nacido en Buenos Aires y en el registro de entrada se lo anotó como pardo, como eran denominados en la época los mestizos, de ascendencia mixta africana y europea o criolla. Estaba casado con Encarnación Castro, con quien tuvo seis hijos: cuatro varones y dos mujeres. En la misma documentación de ingreso, el funcionario que lo entrevistó dejó constancia de que "dice que siempre ha trabajado, tanto en su oficio de zapatero como en otras ocupaciones". ${ }^{8}$ Pero, al final de sus días estaba conchabado bajo la protección de una mujer que le retenía su libreta y le daba por sus prestaciones unos cincuenta pesos mensuales. Visto a través de los ojos de la historiografía de la pobreza urbana, el caso de Posadas pudo ser tomado como el de un afrodescendiente cuya salud estaba deteriorada por la participación en las guerras de independencia y la edad, y que anciano y achacoso buscó hacer uso de la cama y la comida que le procuraban en el Asilo de Mendigos. No obstante, su historia resulta también una oportunidad para hacer otras preguntas con las herramientas de una historia social del trabajo interesada en los artesanos y las artesanas en el Río de la Plata ¿Qué experiencias de trabajo artesanal pudieron tener afrodescendientes como 
Posadas en la primera mitad del siglo XIX? ¿cómo la experiencia de la guerra, la conquista de la libertad, las mudanzas políticas impactaron en la vida y el trabajo de hombres y mujeres pardos, negros, morenos?

Un ejercicio como el que estamos llevando adelante hace posible meditar en torno a la estabilidad de las periodizaciones con las que se ha abordado a la historia del trabajo en el siglo XIX en la región. Al indagar en la vida de artesanos como el zapatero Posadas se abre una puerta para pensar trayectorias laborales en un mercado de trabajo que seguramente sufrió por guerras, conflictos interprovinciales, bloqueos portuarios, transformaciones en las economías trasnacionales, o por el movimiento de personas dentro del territorio o por el Atlántico. Como es asunto sabido, desde la década de 1960, la historiografía laboral inclinó su atención a las últimas décadas del siglo XIX. La justificación de dicho recorte se basó en: las dimensiones del movimiento de personas vía el Atlántico; la formación de gremios por oficio y luego por rama de industria; la existencia de instituciones estatales encargadas de producir información sobre trabajo (Panettieri, 1967; Godio, 1972; Bilsky, 1985; Del Campo, 1986 y Poy, 2014). Pero, el zapatero Posadas, quien se empeñó en que se registre que él había trabajado como tal, lo que involucraba formar parte de un oficio con grados de especialización, como también el pardo Jacinto López de oficio sombrerero, ${ }^{9}$ ola lavandera Ana Gomes, negra y africana, ${ }^{10}$ entre otros trabajadores especializados en la primera mitad del siglo XIX, ponen de relieve la relevancia de ahondar en tales experiencias laborales. Para ello, es preciso definirlas en su propia especificidad histórica.

En la década de 1990, una investigación de Hilda Sábato y Luis Alberto Romero tomó otro rumbo, al indagar en el mercado de trabajo de Buenos Aires en las primeras décadas de la segunda mitad del siglo XIX. Sábato y Romero destacaron que, a lo largo de la década de 1850, la producción estaba dominada por talleres pequeños, organizados tanto por trabajadores por cuenta propia como a cargo de un patrón que contrataba algunos asalariados o asalariadas. Si bien existieron también en ese período establecimientos de mayor tamaño, la evidencia parecía confirmar que la forma de organizar el trabajo seguía las pautas de un viejo sistema basado en una división de tareas al interior de estos espacios de trabajo que replicaba las pautas de los oficios conocidos, los cuales implicaban escalafones y tareas específicas de acuerdo a estos (Sábato y Romero, 1990). Basados en registros estadísticos y en bibliografía secundaria sobre los orígenes de la industria en el país, estos historiadores plantearon que el trabajo artesanal en la ciudad tenía un bajo nivel de especialización, resultado de una demanda que hasta entonces había sido restringida, poco sofisticada y satisfecha en su mayor parte por la importación (Sábato y Romero, 1990). La excepción la constituía el artesanado que se abocaba a la demanda de los sectores de mayor poder adquisitivo. La interpretación de Sábato y Romero consolidó una mirada en la cual pobreza y calificación eran dicotómicas. Pero, trayectorias laborales como la del zapatero Posadas o la lavandera Ana Gomes ponen en entredicho dicha apreciación. Los trabajadores que lo hacían con sus manos, como sastres, zapateros, sombrereros, lavanderas, costureras, no solo podía tener un alto nivel de especialización, sino que también -y pese a esta- podían empobrecerse, cambiar de trabajo, y -en ocasionespasar a depender de otras personas, como sucedió con el zapatero Posadas que quedó conchabado al servicio de una persona que le retenía "su libreta".

Hoy en día, nuevas investigaciones, menos preocupadas en describir las características de ese mercado de trabajo capitalista en formación y más interesados en los y las trabajadoras, han comenzado a preguntarse por cómo la raza y el género incidieron en la configuración de ese mercado laboral. Las evidencias sobre la presencia de pardos, morenos, afrodescendientes y de mujeres en el artesanado porteño o llevando adelante trabajos que requerían de destrezas específicas y de especialización, ponen en cuestión nociones "blanqueadas" y "masculinizadas" de calificación que estaban presentes en aquella historiografía, por la cual quedaron excluidos del análisis afrodescendientes, pardos, morenos y costureras, lavanderas y otras trabajadoras a la hora de pensar en trabajos calificados e intensivos y en el artesanado urbano.

El trabajo del historiador Lyman Johnson forma parte de esta renovación historiográfica al arrojar luz sobre las experiencias de trabajo, vida cotidiana y participación política del artesanado urbano a fines del período colonial y primeros años de la independencia en Buenos Aires. En su investigación se preguntó por cómo 
se estructuraron las jerárquicas relaciones raciales en unos ámbitos de trabajo y el modo en que las mismas dotaron de sentido a las masculinidades que se forjaron en los talleres artesanales (Johnson, 2013).

Entre el período revisado por Johnson y los análisis que sondean los mundos del trabajo a mediados del siglo XIX hay un vacío de estudios, lo que nos aleja de hacer comprensibles experiencias de trabajo y de vida como las del zapatero Posadas, la lavandera Gomes o el sombrerero López, tres trabajadores calificados pobres, de orígenes nacionales y raciales dispares, y que enfermos o lisiados terminaron en un Asilo para pobres. A pesar de las carencias, la pesquisa reciente de la historiadora Mariana Katz brinda pistas para reconocer aspectos de las vidas laborales de artesanos como aquellos que finalizaron sus días en el Asilo a fines de la década de 1850. Por un lado, su estudio reconstruye aspectos del mundo artesanal porteño en la primera mitad del siglo XIX, con particular énfasis en la década de 1830. Por otra parte, arroja luz sobre el peso de los afrodescendientes en los mundos del trabajo artesanal en la primera mitad del siglo XIX. A su vez, Katz logra hacer visible la presencia femenina inserta y oculta en esos talleres artesanales, en tanto que esposas, hermanas e hijas de los artesanos, pero colaborando activamente con la labor cotidiana de producción (Katz, 2017). Su estudio es además una oportunidad de repasar la agencia política, al observar cómo intervinieron por ejemplo para que los aranceles a la importación de manufacturas se mantuvieran lo suficientemente altos como para no aniquilar sus medios de vida.

En otro sentido, historias como la del pardo Posadas permiten reflexionar sobre las opresiones raciales en los ámbitos laborales ¿De qué manera funcionaron las diferencias de raza como elementos que estructuraron jerarquías, divisiones o estigmas en el mundo del trabajo para artesanos y trabajadores negros, morenos y pardos? Las periodizaciones conocidas vuelven a desestabilizarse cuando intentamos detectar estas situaciones para quienes vivieron y trabajaron en Buenos Aires en distintos momentos del siglo XIX.

Para los funcionarios del Asilo de Mendigos dejar constancia de la raza y patria de cada una de las personas que ingresaban resultaba una preocupación equivalente a la de anotar la ocupación o la dolencia que aquejaba y justificaba la permanencia en la institución. Del total de asilados y asiladas, veintinueve fueron listados como negro, negra, moreno, morena, pardo, parda. La casi totalidad de las personas registradas como negro y moreno figuran como nacidas en África, pero también hay uno nacido en Lima y una nacida en Tucumán. ${ }^{11}$ Es posible, entonces, revisar esta fuente con los aportes de una historiografía interesada en interrogar por los procesos de racialización y subalternización en el Río de la Plata. Un estudio reciente de Alex Borucki sobre identidades negras rioplatenses entre 1760-1860 resulta de utilidad para adentrarnos en los resabios históricos en las formas de nombrar a las y los afrodescendientes. En las sociedades coloniales españolas, "negro" hacía alusión a una persona de ascendencia subsahariana plena. "Moreno" se convirtió rápidamente en un eufemismo para "negro"; y "pardo" refería a una persona de ascendencia mixta -africana + europea, criolla o indígena- (Borucki, 2017). No obstante, cabe remarcar que las divisiones sociales en castas que caracterizaron el período colonial -y que adquirieron una nueva fuerza con la extensión del comercio esclavista desde la capital virreinal en el último tercio del siglo XVIII- no estuvieron tan sólo basadas en consideraciones fenotípicas, las cuales eran a su vez significadas socialmente. Las distinciones y jerarquizaciones se realizaron a partir de una combinación de elementos imbricados entre los que se contaban la apariencia física (color, rasgos, vestimenta), el estatus económico, los vínculos familiares y la ocupación (Candioti, 2017), y esto podía ser activamente negociado por las personas racializadas.

La investigación de Magdalena Candioti describe algunos de los movimientos que entre 1810 y 1860 existieron para pensar la afrodescendencia, el color y el pasado esclavo como marcas entrelazadas de distinción y subalternización (Candioti, 2017). Explica que, a pesar de instalarse un cierto sentido común que asociaba el fin de la colonia a la disolución de un orden racial, siguió habiendo discriminación hacia africanos y africanas y afrodescendientes. Su investigación, entonces, ayuda a comprender los contornos raciales que adquirieron unas ideas sobre la ciudadanía y permite imaginar el sustrato experiencial de esos debates en las vidas de trabajadores y trabajadoras negras. Aunque la experiencia sufragista fue amplia desde los años 1820, y las restricciones raciales para el voto fueron borrándose, conforme nuevos ensayos de gobierno republicano 
se iban desarrollando, ¿ocurría lo mismo en otros ámbitos? Precisamente, ¿tuvo esto correlato en los mundos del trabajo? Las respuestas a estas preguntas requieren de nuevas investigaciones empíricas. Algunas exploraciones recientes han detectado cómo en los talleres artesanales, vinculados a las manufacturas textiles, en la década de 1850 se dieron diversos arreglos laborales basados en la coacción y que implicaban relaciones jerárquicas, autoritarias, con libertades coartadas, controles sobre las y los trabajadores o trabajadoras negras, pardas o morenas dependientas de parte de patrones o patronas (Mitidieri, 2017).

Mientras en los talleres las relaciones laborales podrían implicar violencias y discriminación, pardos, negras o morenos continuaron pujando para limitar tales atropellos, recurrieron a la Justicia, organizaron sus propios espacios de sociabilidad y demandaron que el gobierno educara a sus hijas (Mitidieri, 2018a; Miranda Pereira, 2011 y Barrachina, 2017). Tales estudios exploratorios ponen en evidencia instancias de negociación, acuerdos y tensiones en las cuales pardos, morenos, y afrodescendientes participaron y que, seguramente, permearon a sus relaciones laborales. Por último, estudios sobre sociabilidad, identidad y cultura permiten observar cómo estos espacios de solidaridad y ayuda mutua funcionaron frente a las adversidades y violencias cotidianas propias de la esclavitud, transformándose a medida en que el siglo XIX avanzó en instancias de actuación política y de vinculación con funcionarios y políticos ¿Fueron estas asociaciones también parte de redes de trabajo para artesanos pardos, negros o morenos? Faltan estudios al respecto. Mas recapacitar sobre las trayectorias de artesanos y artesanas, meditar en torno a las periodizaciones adjudicadas al trabajo artesanal y cuestionar las formas en que las relaciones de género y las raciales operaron en esos mundos del trabajo, posibilitarían otorgar un lugar en la historia del trabajo artesanal a varones como el sombrerero Jacinto López, el zapatero Juan Manuel Posadas y Ana Gomes lavandera y portadora de un conjunto de destrezas que hacían de sus labores un trabajo intensivo y especializado.

\section{Mujeres, trabajos y taReas en las casas}

El día 4 de febrero de 1859 ingresó al asilo Juana Burgos. ${ }^{12}$ Según su relato, había estado casada con José Lopes Camello, el cual había fallecido hacía 40 años. Sus dos hijos, Clara y Juan Pedro, eran pobres y vivían de su trabajo. Esta señora de 70 años declaró como oficio el de costurera y planchadora. Hacía nueve años que estaba ciega, y por eso no trabajaba. Sobrevivía gracias a los auxilios de Doña Josefa Almeida, una mujer de la que Juana había sido nodriza. Un mes más tarde llegó a la institución María Capdevila. Registrada en la documentación como "morena" y nacida en frica, la mujer de 60 años dio testimonio de que había sido esclava de Don Pedro Capdevila y de un gallego llamado Don Benito. Fue en la estancia de Capdevila en donde se casó con Pedro Barragán. Declaró el oficio de cocinera. Tal vez fuera con esa ocupación que reuniera los dineros que guardaba entre sus ropas o "andrajos", tal como les llamó el funcionario que la recibió. ${ }^{13}$

Estas dos experiencias, brevemente sintetizadas en el registro diario de ingresos del Asilo, aportan elementos para ensanchar los análisis existentes en términos de pobreza urbana. En las vidas de Juana y de María su ocupación, sus trabajos y quehaceres cotidianos, sus formas de ganarse la vida fueron actividades en las que lo laboral, lo familiar, la casa del patrón o la patrona aparecían como experiencias entrelazadas, por momentos, indistinguibles entre sí. Sirvientes y sirvientas, tal como eran comúnmente denominados en los papeles de época, se ocuparon de las tareas de servir en las casas de sus patrones o patronas. Servir involucraba diversas ocupaciones; entre las tareas que solían recaer sobre mujeres y niñas empleadas en el trabajo de servir se contaban limpiar, cocinar, lavar la ropa, remendarla, plancharla, servir la mesa, criar, cuidar y amamantar niños, enseñarles tareas, entre otras.

Desde hace décadas, la historia del trabajo se ha preguntado por las mujeres. Inicialmente, el empeño estuvo orientado a describir cómo las mujeres se habían integrado y participado en el mercado laboral a lo largo del tiempo. Diversas investigaciones, en las décadas de 1980 y 1990, se refirieron a las características de dicha participación, a las condiciones de trabajo, calificación y remuneración. A partir de los censos nacionales de población, desglosaron algunos de los determinantes de la participación femenina en el mercado de trabajo 
como la edad, el estado civil, el nivel educativo, la condición de migración, el asentamiento urbano-rural y las diferencias ocupacionales por sexo. Las lecturas sobre estos registros estadísticos explicaron cómo ciertas decisiones políticas habían afectado a la definición y a la medición del trabajo de las mujeres, reproduciendo a la par las jerarquías y desigualdades entre los sexos.

Al centrar la atención en el mercado de trabajo a mediados de siglo XIX, los estudios son escasos. Es necesario volver a la investigación de Sábato y Romero (1992) para reconocer como estos historiadores lo describieron e incorporaron a las mujeres. Ellos indicaron que Buenos Aires contaba con un abultado servicio doméstico, donde en la ciudad representaba alrededor de un $20 \%$ de la población activa. Las mujeres predominaban en casi todas las ocupaciones y el servicio doméstico concentraba a más de la mitad de las trabajadoras, es decir una de cada cuatro mujeres se desempeñaba en este. Para estos autores, la división sexual del trabajo era tajante, de manera tal que pocos oficios concentraban casi todo el empleo femenino (Sábato y Romero, 1992).

Hoy en día, algunas afirmaciones de ese estudio pueden ser rebatidas. La pesquisa de Hernán Otero hizo posible reconocer la relación entre política e información censal y poner en duda la transparencia de los datos censales. En el Primer Censo Nacional de Población llevado adelante en 1869, quienes lo confeccionaron no solo no incorporaron dimensiones raciales y étnicas como tampoco diferenciaron las ocupaciones laborales de acuerdo al sexo. Las ocupaciones se señalaron como masculinas a excepción de algunas como la costura, el lavado, el planchado, la prostitución y aquellas vinculadas al servicio doméstico, que eran compartidas por varones y mujeres (Otero, 2006). La no inscripción de interrogaciones relativas a la dimensión racial se habría reconocido y avalado con argumentos técnicos: la supuesta dificultad de medición de la variable, ya que las categorías (blanco, negro, mulato, pardo) no estaban fundadas en aspectos físicos sino negociables, que a lo largo del tiempo se habían adecuado a una serie de características, tales como el estatus legal, las vestimentas, el lugar de residencia, la alimentación, las costumbres, entre otras (Pita, 2017). Sin embargo, detrás de dicha justificación se encubrieron decisiones ideológicas que involucraron una política de blanqueamiento. Algo semejante sucedió con los trabajos de las mujeres: qué ingresó como trabajo y qué quedó excluido no fue un reflejo de las labores y tareas laborales en sí mismas, es decir de cómo las mujeres trabajaban para ganarse la vida, sino del valor que unos contemporáneos le otorgaron.

Existen largas reflexiones sobre el trabajo doméstico, la división entre trabajo productivo y reproductivo, la doble jornada laboral femenina, entre otras cuestiones. Varios de estos debates que se gestaron en los años 1970 (Dalla Costa y James, 1974; Federici, 1975 y Cox y Federici, 1976) develaron aspectos y dimensiones no consideradas por la historiografía del trabajo, y que de distintas formas fueron resignificadas en investigaciones recientes (Acha, 2013; Allemandi, 2017; Pérez, 2013, 2015a, 2015b, 2016 y Remedi, 2012, 2014). Algunas de estas reflexiones colaboran para pensar históricamente las experiencias situadas de mujeres como Juana Burgos y María Capdevila, quienes realizaron trabajos de servir en el segundo tercio del siglo XIX en Buenos Aires.

A lo largo de su vida, Juana Burgos desplegó diferentes estrategias para ganarse la vida: había planchado, cocido y amamantado. Haber sido nodriza de Doña Josefa Almeida, hizo posible que, al quedar ciega, aquella mujer la auxiliase para su sobrevivencia. Las ayudas de Almeida tendrían base en un lazo laboral que había dado lugar a un vínculo a lo largo del tiempo, en el cual es posible incluir tanto sentidos morales de auxilio a alguien que se consideraba una dependiente como un lazo afectivo hacia quien había sido su ama de leche. La investigación de Cecilia Allemandi para fines del siglo XIX y comienzos del XX, permite saber de las características del trabajo de ama de leche. Este era un medio de vida para un sector de mujeres. Algunas de las nodrizas formaban parte del llamado servicio doméstico, viviendo en la casa del niño o niña a criar y recibiendo una remuneración no siempre ni necesariamente en dinero: techo, comida, vestido podrían ser parte de la contraprestación. Otras lo hacían en sus propios lugares de morada, recibiendo exiguos salarios por la crianza y cuidado de recién nacidos provenientes de familias trabajadoras o jóvenes solteras que debían subsistir por sus propios medios (Allemandi, 2017). Es probable que Juana amamantase a Josefa al momento 
de convertirse en madre de alguno de sus dos hijos y que de algún modo continuara estando en la casa de Almeida como criada, nodriza, sirvienta, todas faenas que implicarían trabajos de cuidado. De momento, sólo contamos con el registro que dejó asentado el funcionario que recibió a Juana en el asilo. Pero el hecho de que siguiera siendo asistida por alguien a quien había amamantado, es un elemento a atender a la hora de indagar en estos vínculos laborales, de dependencia y tal vez afectivos. Explorar estas dimensiones de la experiencia laboral de las mujeres resulta clave para reconstruir esos mundos del trabajo en la primera mitad del siglo XIX que tenían a la casa, los cuidados y el servir como centro.

\section{A MODo DE CONCLUSión}

A lo largo de este artículo nos propusimos el ejercicio de reflexionar acerca de las posibilidades historiográficas de una fuente que conocimos enmarcada en la tradición de los estudios de la pobreza urbana, de las instituciones de asistencia a pobres, y de las prácticas de beneficencia como respuestas al fenómeno de la marginación, el pauperismo y la indigencia, entre personas sin redes familiares, enfermas, ancianas o lisiadas. Al partir de una evidencia que consignó datos de distinta índole sobre las vidas y los trabajos de las personas que de alguna manera buscaron o aceptaron ser ingresadas al Asilo de Mendigos de la ciudad de Buenos Aires, nuestra intención fue la de hacer próximo el desafío de reflexionar historiográficamente sin perder de vista el trabajo que otros historiadores e historiadoras se tomaron con las fuentes documentales.

Inspiradas en la perspectiva de una historia social que busca describir las experiencias sociales de hombres y mujeres que no dejaron testimonios escritos por sus propias manos, entendemos que es posible y deseable volver a unir aquello que la segmentación analítica o historiográfica separó. En tal dirección, la intención de este trabajo fue la de problematizar unos recorridos historiográficos a la luz de ciertos interrogantes que pueden realizarse a esta documentación, y que hacen factible examinar relaciones, periodizaciones y problemas históricos. Nuestro punto de partida fue, entonces, plantear preguntas que permitan cruzar las fronteras historiográficas para reflexionar sobre trabajo y pobreza como dimensiones entrelazadas en una misma trayectoria vital, ya sea porque la ocupación laboral no alcanzaba para garantizar el sustento, porque diferentes acontecimientos políticos incidieron en la estabilidad de ciertos trabajadores y trabajadoras o porque el estado de salud o la viudez de algunas mujeres hacía más difícil el ganarse la vida. Ya como alternancia a lo largo de la biografía, ya como experiencia de trabajadores y trabajadoras pobres, negros, africanas, pardas o morenos, una perspectiva que tome en consideración las diferentes estrategias de sobrevivencia de dichas personas complejiza la mirada y otorgaría dinamismo a las descripciones históricas de una enrevesada primera mitad del siglo XIX en Buenos Aires.

Enfocar en los mundos del trabajo por los que transcurrieron asilados y asiladas ha sido una oportunidad para adentrarse en la diversidad de ocupaciones existentes en la primera mitad del siglo XIX. Los diferentes aportes realizados por la historiografía que se ocupa de dichos mundos brindan elementos de suma relevancia para profundizar en el estudio del artesanado porteño, revisando algunas de las formas en que se ha periodizado y delimitado la relevancia del trabajo del artesanado e invitando a reconsiderarlo también a partir de una mirada atenta a las relaciones de género y a las relaciones raciales que operaron en dichos mundos. En un sentido semejante, hemos buscado preguntar sobre las experiencias y modalidades de quienes trabajaron en casas y residencias de otros y otras, que declararon ocupaciones y relaciones laborales que podían incorporarse en el rubro de servicio doméstico o no, que podían estar consideradas en otros registros, como los censales o no. Tales ambigüedades invitan a llevar adelante nuevas investigaciones que a la par de reflexionar sobre las formas en que el género y la raza estuvieron presentes y vertebraron las relaciones en los mundos del trabajo, en las casas, en los talleres, permitan también reconocer más acabadamente los significados sociales del trabajo en una época en la cual ya no se pueden dar por sentadas definiciones, características y relaciones a vista de lo que sucedió luego. 
En suma, este ejercicio intentó seguir unas pistas en torno a las trayectorias laborales de hombres y mujeres, libres o libertos, negros o morenas, pobreza y trabajo, trabajo especializado, trabajos de servir, relaciones de género y de raza, con el sentido de hacer palpable la posibilidad de considerar unas experiencias de trabajo, en un tiempo atravesado por guerras, cambios políticos, discriminaciones raciales, violencias varias y la zozobra de ganarse la vida día a día demandó estrategias diversas.

\section{Bibliografía}

Acha, O. (2013). La organización sindical de las trabajadoras domésticas durante el primer peronismo. Rems, Año 5/6, $\mathrm{N}^{\circ}$ 5/6. Noviembre 2012/2013, 27-39.

Allemandi, C. (2012). El servicio doméstico en el marco de las transformaciones de la ciudad de Buenos Aires, 1869-1914. Diálogos, 16(2), 385-415. Recuperado de https://www.redalyc.org/pdf/3055/305526885002.pdf

Allemandi, C. (2014). Una aproximación al servicio doméstico a partir de las "colocaciones". Ciudad de Buenos Aires (fines del siglo XIX y principios del XX). Serie Documentos para Discusión, IDES- PESEI, 3, 1-39.

Allemandi, C. (2015). Sirvientes, criados y nodrizas. Una aproximación a las condiciones de vida y de trabajo en la ciudad de Buenos Aires a partir del servicio doméstico (fines del siglo XIX-principios del XX). (Tesis doctoral inédita). Universidad de San Andrés, Buenos Aires.

Allemandi, C. (2015). Niños Sirvientes y “criados": el trabajo infantil en el servicio doméstico (ciudad de Buenos Aires, fines del siglo XIX-principios del siglo XX). Cuadernos del IDES, 30, 11-38. Recuperado de http://ides.org.ar/ wp-content/uploads/2012/03/Cuadernos-del-IDES-N\%C2\%BA-30-Octubre-2015.pdf

Allemandi, C. (2016). Entre tentativas reglamentarias y sirvientes organizados: la regulación municipal del servicio doméstico en la ciudad de Buenos Aires a fines del siglo XIX y principios del siglo XX. Revista Historia y Justicia, 6, 103-136. Recuperado de http://rhj.revues.org/556

Allemandi, C. (2017). Sirvientes, criados y nodrizas. Una historia del servicio doméstico en la ciudad de Buenos Aires (fines del siglo XIX y principios del XX). Buenos Aires: Ed. Teseo.

Allemandi, C. (2017). Entre dinámicas familiares y formas de crianza: las amas de leche y el abandono de niños a su cuidado en la ciudad de Buenos Aires (fines del siglo XIX-principios del XX). En A. Abramowski y S. Canevaro (Comp.), Pensar los afectos. Aproximaciones desde las ciencias sociales y las humanidades (pp. 97-116). Buenos Aires: Ed. UNGS.

Barrachina, M. A. (2017). Una escuela para las niñas de color: raza, género y clase en el Buenos Aires posrevolucionario. En Actas de las XIII Jornadas de Historia de las Mujeres. Universidad de Buenos Aires.

Barrancos, D. (2000). Inferioridad jurídica y encierro doméstico.En F. Gil Lozano, V. Pita y M.G. Ini (Dirs.), Historia de las mujeres en la Argentina (pp. 111-127). Siglo XIX. Tomo I. Buenos Aires: Taurus.

Barrancos, D. (2007). Mujeres en la sociedad argentina. Una historia de cinco siglos. Buenos Aires: Ed. Sudamericana.

Bentancur, A. y Aparicio, F. (2006). Amos y esclavos en el Rio de la Plata. Buenos Aires: Planeta.

Beretta Curi, A. (2015). Inmigración europea y artesanado en América Latina (1814-1914). Notas sobre algunos temas y problemas, a modo de presentación. Revista THEOMAI, 31. Recuperado de http://revista-theomai.unq.edu. ar/NUMERO_31/0.BeretaCuri.pdf

Bilsky, E. (1985). La F.O.R.A. y el movimiento obrero (1900 - 1910). Buenos Aires: CEAL.

Borucki, A. (2017). De compañeros de barco a camaradas de armas. Identidades negras en el Río de la Plata, 1760-1860. Buenos Aires: Ed. Prometeo.

Bravo, M. C., Gil Lozano, F. y Pita, V. (2007). Historia de luchas, resistenciasy representaciones. Mujeres en la Argentina. Tucumán: EDUNT.

Candioti, M. (2010). Altaneros y libertinos. Transformaciones de la condición jurídica de los afroporteños y las disputas judiciales sobre su estatus en la Buenos Aires revolucionaria (1810-1820). Desarrollo Económico. Revista de Ciencias Sociales, 50(198). 
Candioti, M. (2017). Ciudadanos negros en el Río de la Plata. Repensar la inclusión política de los emancipados entre la revolución y la constitución. Revista Estudios Sociales, 53, 183-213.

Carrizo, M. (2016). Artesanos afrodescendientes en Córdoba (Siglo XIX). En F. Guzmán, L. Geler y A. Frigerio (Eds.), Cartografias afrolatinoamericanas. Perspectivas situadas desde la Argentina. Buenos Aires: Ed. Biblos.

Chalhoub, S. (1990). Visôes da liberdade: uma história das últimas décadas da escravidão na corte. Sao Paulo: Camara Brasileira do Livro.

Cox, N. y Federici, S. (1976). Counter-Planning from the Kitchen: Wages for Housework: a Perspective on Capital and the Left. Nueva York: New York Wages for Housework Committee.

Cruz, E. (2008). Pobreza, pobres y política en el Río de la Plata. Boletín del Instituto de Historia Argentina y Americana Dr. Emilio Ravignani, 30, 101-117.

Cruz, E. (2013). Pobreza, pobres y política social en el Río de la Plata. Trashumante, Revista Americana de Historia Social, 1(1).

Dalla Costa, M. y James, S. (1975). The Power of Women and the Subversion of the Community. Bristol: Falling Wall Press Ltd.

Del Campo, H. (Comp). (1986). El sindicalismo revolucionario: 1905-1945. Buenos Aires: CEAL.

Di Meglio, G. (2017). El saqueo y la muerte. El día después de la batalla de Caseros en Buenos Aires. En Di Meglio, G. y S. Serulnikov (Eds.), La larga historia de los saqueos en Argentina. Buenos Aires: Ed. Siglo XXI.

Federici, S. (1975). Wages Against Housework. Nueva York: Ed. Power of Women Collective / Falling Wall Press.

Garavaglia, J. C. y Gelman, J. (1998). Mucha tierra y poca gente: un nuevo balance historiográfico de la historia rural platense (1750-1850). Revista Historia Agraria, 15, 29-50.

Geler, L. (2010). Andares negros, caminos blancos: afroporteños, estado y nación. Argentina a fines del siglo XIX. Rosario: Prohistoria.

Gil Lozano, F. et al. (Dirs.). (2000). Historia de las mujeres en la Argentina. Siglo XX. Buenos Aires: Ed. Taurus.

Godio, J. (1972). El movimiento obrero y la cuestión nacional. Argentina: inmigrantes asalariados y lucha de clases 1880-1910. Buenos Aires: Erasmo.

Godio, J. (1985). El movimiento obrero argentino (1870-1910). Socialismo, Anarquismo y Sindicalismo. Buenos Aires: Legasa.

Goldberg, M. (1997). Negras y mulatas de Buenos Aires 1750-1850. Ponencia presentada en el $49^{\circ}$ Congreso Internacional de Americanistas, Quito.

Goldberg, M. (2000). Las afroargentinas. 1750-1880. En F. Gil Lozano et al., Historia de las mujeres en la Argentina [Tomo I] (pp. 71-73). Buenos Aires: Ed. Taurus.

Guzmán, T. (2014). La estructura ocupacional y la economía urbana de Buenos Aires a mediados del siglo XIX, 1827-1855. Ponencia presentada en las XXIV Jornadas de Historia Económica. UNR.

Illades, C. (1996). Hacia la república del trabajo. La organización artesanal en la ciudad de México. 1853-1876. D.F.: Ed. Colegio de México.

Johnson, L. (2007). A Lack of Legitimate Obedience and Respect: Slaves and their Masters in the Courts of Late Colonial Buenos Aires. HAHR, 4(87), 631-57.

Johnson, L. (2011). Workshop of Revolution. Plebeian Buenos Aires and the Atlantic World, 1776-1810. Durham and London: Duke University Press.

Johnson, L. (2013). Los talleres de la revolución. La Buenos Aires plebeya y el mundo del Atlántico, 1776-1810. Buenos Aires: Ed. Prometeo.

Katz, M. (2017). Los artesanos proteccionistas. Buenos Aires, primera mitad del siglo XIX. Economía y Politica, 4(2), 5-36.

Lechini, G. (2008). Los estudios afroamericanos y africanos en América Latina. Buenos Aires: CLACSO.

Lobato, M. (Ed.) (2000). El progreso, la modernización y sus límites. Buenos Aires: Sudamericana. 
Lobato, M. (2001). La vida en las fábricas. Trabajo, protesta y politica en una comunidad obrera, Berisso (1904-1970). Buenos Aires: Prometeo.

Lobato, M. (2007). Historia de las trabajadoras en Argentina, 1869-1960. Buenos Aires: Edhasa.

Mallo, S. (2004). Pobreza y formas de subsistencia en el Virreinato del Río de la Plata a fines del siglo XVIII. En Mallo, S., La sociedad rioplatense ante la justicia. La Plata: Archivo Histórico de la Provincia de Buenos Aires, Dr. Ricardo Levene.

Martínez Cuesta, A. (1995). Las monjas en la América colonial. 1530-1824. Thesaurus Boletín del Instituto Caro y Cuervo. 50(1-3), 572-626.

Mitidieri, G. (2017). Costureras, modistas, sastres y aprendices. Una aproximación al circuito de trabajo de la costura. Buenos Aires, 1852-1862 (Tesis de Licenciatura en Historia). Facultad de Filosofía y Letras. Universidad de Buenos Aires.

Mitidieri, G. (2018a). Entre modistas de París y costureras del país. Espacios de labor, consumo y vida cotidiana de trabajadoras de la aguja, Buenos Aires, 1852-1862. Trashumante. Revista Americana de Historia Social, 12, 8-29. doi: https://doi.org/10.17533/udea.trahs.n12ao2

Mitidieri, G. (2018b). "Por cobro de pesos". Nociones de trabajo y honor en las estrategias legales de modistas, sastres y roperos ante trabajos impagos. Buenos Aires en la década de 1850. Ponencia presentada en el Seminario Internacional Historia del Trabajo y los Trabajadores. Siglos XVIII - XX. UAM Iztapalapa.

Miranda Pereira, L. A. (2011). Do Congo ao Tango: associativismo, lazer e identidades entre os afro-portenhos na segunda metade do século XIX. Revista Mundos do Trabalho, 3(6), 30-51. doi: https://doi.org/10.5007/1984 $-9222.2011 \mathrm{v} 3 \mathrm{n} 6 \mathrm{p} 30$

Moreno, J. L. (2000). La política social antes de la politica social: (caridad, beneficencia y politica social en Buenos Aires, siglos XVII a XX), Buenos Aires, Ed. Prometeo.

Moreno, J. L. (2012) Un asilo para los pobres. Los mendigos y sus historias de vida (Buenos Aires a mediados del siglo $X I X)$. Rosario: Ed. Prohistoria.

Nari, M. (2002). El trabajo a domicilio y las obreras (1890-1918). Razón y Revolución, 10, 2-13. Recuperado de http ://revistaryr.org.ar/index.php/RyR/article/viewFile/271/288

Nari, M. (2004). Politicas de maternidad y maternalismo politico. Buenos Aires: Biblos.

Otero, H. (2006). Estadística y nación. Una historia conceptual del pensamiento censal de la Argentina moderna, 1869-1914. Buenos Aires: Ed. Prometeo.

Panettieri, J. (1967). Los Trabajadores. Buenos Aires: Ed. Jorge Alvarez.

Panettieri, J. (1984). Las primeras leyes obreras. Buenos Aires: CEAL.

Parolo, P. (2005-2006). Nociones de pobreza y políticas hacia los pobres en Tucumán en la primera mitad del siglo XIX. Población y Sociedad, 12/13, 137-168.

Perez Toledo, S. (1996). Los hijos del trabajo. Los artesanos de la ciudad de México. 1780-1853. D.F.: Ed. Colegio de México - UAM.

Pérez, I. (2016). Hurto, consumo y género en el servicio doméstico (Mar del Plata, 1950-1980). Anuario IEHS, 31(2), 57-78.

Pérez, I. (2015a). Una línea fluctuante: el servicio doméstico y el régimen de accidentes de trabajo (Argentina, 1915-1956). Estudios Sociales, 49(2),155-182. doi: https://doi.org/10.14409/es.v49i2.5132

Pérez, I. (2015b). Un "régimen especial" para el servicio doméstico. Tensiones entre lo laboral y lo familiar en la regulación del servicio doméstico en la Argentina, 1926-1956. Cuadernos del IDES, 30, 44-67. Recuperado de h ttp://ides.org.ar/wp-content/uploads/2012/03/Cuadernos-del-IDES-N\%C2\%BA-30-Octubre-2015.pdf

Pérez, I. (2013). Entre las normas y sus usos: Servicio doméstico, trabajo, intimidad y justicia en el Consejo de Trabajo Doméstico (Buenos Aires, 1956-1962). Nuevo Mundo, Mundos Nuevos, Marzo 2013, 1-17. doi: http://dx.doi. org/DOI:10.4000/nuevomundo.65167 
Pita, V. (2009). Nos termos de suas benfeitoras: encontros entre trabalhadoras e as senhoras da sociedade de beneficência, Buenos Aires, 1852-1870. Revista Mundos do Trabalho, 1(2), 41-65. doi: https://doi.org/10.500 7/1984-9222.2009v1n2p41

Pita, V. (2012).La casa de las locas. Una historia social del Hospital de Mujeres Dementes. Buenos Aires, 1852-1890. Rosario: Ed. Prohistoria.

Pita, V. (2013). De trabajos, demandas y limosnas o los modos de vivir en la ciudad de Buenos Aires, 1852-1880. Seminario Permanente de Historia Social, Colegio de Mexico, DF.

Pita, V. (2014). De negociaciones cotidianas y de posibilidades históricas: una aproximación a los intercambios entre médicos y trabajadoras. Buenos Aires, 1870 -1940. Anuario de Historia Regional y de las Fronteras, 19(2), 365-390.

Pita, V. (2016). Historia social del Trabajo en perspectiva de género en Argentina: aspectos de un entramado en construcción. En S. Pérez Toledo y S. Paolo Solano (coords.), Pensar la bistoria del trabajo y de los trabajadores en América, siglos XVIII y XIX (pp. 183-201). Madrid-Frankfurt: Iberoamericana/Vervuert.

Pita, V. (2017). El género de la historia del trabajo: lecturas y dilemas situados. Buenos Aires, segunda mitad del siglo XIX. En S. Bandieri, S. Fernández (coords.), La historia argentina en perspectiva localy regional. Nuevas miradas para viejos problemas [Tomo 3] (pp. 255-270). Buenos Aires: Teseo.

Pita, V. (2018). Auxilios, costuras y limosnas. Una aproximación a las estrategias de sobrevivencia de trabajadoras pobres en la ciudad de Buenos Aires. 1852-1870. Estudios del ISHiR, 8(20), 135-151.

Popinigis, F. (2012). “Aos pés dos pretos e pretas quitandeiras": experiências de trabalho e estratégias de vida em torno do primeiro mercado público de desterro, 1840-1890. Revista Afro-Ásia, 46,193-226.

Popinigis, F. (2015). Trabajo, libertad y esclavitud: estrategias y negociaciones en el sur de Brasil, siglo XIX. Trashumante. Revista Americana de Historia Social, 6, 146-168.

Poy, L. (2014). Los orígenes de la clase obrera argentina. Huelgas, sociedades de resistencia y militancia política en Buenos Aires (1888 - 1896).

Rebagliati, L. (2013). ¿Miserables desvalidos o haraganes ociosos? Pobreza y elites en el Buenos Aires virreinal. Foros de Historia política, dependiente de la revista PolHis, s/p. Recuperado de http://historiapolitica.com/datos/fo ros/foro_sectpopulares_rebagliati.pdf

Rebagliati, L. (2013). Los pobres ante la Justicia: discursos, prácticas y estrategias de subsistencia en Buenos Aires (1785-1821). Boletin del Instituto de Historia Argentina y Americana Dr. Emilio Ravignani, $3^{\circ}$ Serie, Facultad de Filosofía y Letras, Universidad de Buenos Aires.

Rebagliati, L. (2014). Negros y mulatos pobres en Buenos Aires (1786-1821). Quinto Sol, 18(1).

Remedi, F. (2012). "Esta descompostura general de la servidumbre." Las trabajadoras del servicio doméstico en la modernización argentina. Córdoba, 1869-1906. Revista Secuencia, 84, 43-69.

Remedi, F. (2014). Las trabajadoras del servicio doméstico: entre la subordinación y la negociación en una modernización periférica. Córdoba (Argentina), 1910-1930. Anuario de Historia Regional y de las Fronteras; vol. $19,423-450$.

Rockman, S. (2009). Scraping By: Wage Labor, Slavery and Survival in Early Baltimore (Studies in Early American Economy and Society from the Library Company of Philadelphia). Baltimore: The Johns Hopkins University Press.

Rosal, M. A. (1994). Negros y pardos en Buenos Aires, 1811-1860. Anuario de Estudios Americanos, 51(1), 165-183.

Rosal, M. A. (2006) Diversos aspectos atinentes a la situación de los afroporteños a principios del período postrevolucionario derivados del estudio de testamentos de morenos y pardos. Consejo Superior de Investigaciones Científicas. Instituto de Historia; Revista de Indias, LXVI, 237, 12-2006; 393-423.

Rosal, M. A. (2009). Africanos y afrodescendientes en el Río de la Plata: siglos XVIII-XIX. Buenos Aires: Editorial Dunken.

Sábato, H. y Romero, L. A. (1990). Artesanos, oficiales, operarios: trabajo calificado en Buenos Aires. 1854-1887. En D. Armus, Mundo urbano y cultura popular (pp. 219-250). Buenos Aires: Ed. Sudamericana. 
Sábato, H. y Romero, L. A. (1992). Los trabajadores de Buenos Aires. La experiencia del mercado: 1850-1880. Buenos Aires: Ed. Sudamericana.

Saguier, E. (1989). La naturaleza estipendiaria de la esclavitud urbana colonial. El caso de Buenos Aires en el siglo XVIII. Revista Paraguaya de Sociología, 74, 45-54.

Saguier, E. (1995). La crisis social, la fuga esclava como resistencia rutinaria y cotidiana. Revista de Humanidades y Ciencias Sociales, 1(2), 115-184.

Saguier, E. (1997). Cimarrones y bandoleros. El mito de la docilidad esclava en la historia colonial rioplatense. Ponencia presentada en el II Encuentro Chileno Argentino de Estudios Históricos, Santiago de Chile.

Schettini, C. (2006). Esclavitud en blanco y negro: elementos para una historia del trabajo sexual femenino en Buenos Aires y en Río de Janeiro a fines del siglo XIX. Entrepasados, 29, 43-62.

Secreto, V. (2010). Justicia na desigualdade: ações de liberdade, papeis de venda e preço justo. Rio da Prata, 1776-1815. Revista Afro-Asia, 42, 27-62.

Secreto, V. (2012). Os escravos de Buenos Aires. Do terceiro pátio à rua: a busca do tolerável (1776-1814). Tempo, 16(33), 23-49.

Secreto, V. (2013). Negros em Buenos Aires. Rio de Janeiro: Mauad Editora.

Socolow, S. (2016). Las mujeres en la América Latina colonial. Buenos Aires: Ed Prometeo.

\section{Notas}

1 Archivo General de la Nación (en adelante AGN), Documentos Escritos (en delante DE), Biblioteca Nacional (en adelante BN), 342-F8, Apuntes del movimiento del Asilo de Mendigos de Buenos Aires, por Antonio Pillado, Nro. 2, Rosa Represa.

2 AGN, DE, BN, 342-F8, Apuntes del movimiento del Asilo de Mendigos de Buenos Aires, por Antonio Pillado, Nro. 26, Mariano Reinoso.

3 AGN, DE, BN, 342-F8, Apuntes del movimiento del Asilo de Mendigos de Buenos Aires, por Antonio Pillado, Nro.62, María Carreras.

4 AGN, DE, BN, 342-F8, Apuntes del movimiento del Asilo de Mendigos de Buenos Aires, por Antonio Pillado, Nro. 8, Juana María Achaval.

5 La distinción entre trabajadores/as y artesanos/as a lo largo del artículo recupera las categorías nativas que aparecen en la fuente analizada, es decir, su uso no implica una definición conceptual. También intenta situar históricamente la diferencia entre quienes habían sido formados en un oficio artesanal y quienes no.

6 AGN, DE, BN, 342-F8, Apuntes del movimiento del Asilo de Mendigos de Buenos Aires, por Antonio Pillado, Nro. 5, Miguel Bosh.

7 AGN, DE, BN, 342-F8, Apuntes del movimiento del Asilo de Mendigos de Buenos Aires, por Antonio Pillado, Nro.32, Francisco del Pino.

8 AGN, DE, BN, 342-F8, Apuntes del movimiento del Asilo de Mendigos de Buenos Aires, por Antonio Pillado, Nro. 142, Juan Manuel Posadas.

9 AGN, DE, BN, 342-F8, Apuntes del movimiento del Asilo de Mendigos de Buenos Aires, por Antonio Pillado, Nro. 6, Jacinto López.

10 AGN, DE, BN, 342-F8, Apuntes del movimiento del Asilo de Mendigos de Buenos Aires, por Antonio Pillado, Nro. 35, Ana Gomes.

11 AGN, DE, BN, 342-F8, Apuntes del movimiento del Asilo de Mendigos de Buenos Aires, por Antonio Pillado, Nro. 33, Lucas Rospillot y Nro. 36, Delfina Pintos.

12 AGN, DE, BN, 342-F8, Apuntes del movimiento del Asilo de Mendigos de Buenos Aires, por Antonio Pillado, Nro.119, Juana Burgos.

13 AGN, DE, BN, 342-F8, Apuntes del movimiento del Asilo de Mendigos de Buenos Aires, por Antonio Pillado, Nro.130, María Capdevila. 